\title{
ON THE DEPTH OF TOPOLOGICAL SPACES*
}

\section{J. GERLITS ${ }^{1}$}

ABSTRACT. In this short note we prove that Kowalsky's starspace of weight $\omega_{1}$ is a suitable counterexample to a conjecture of I. Juhàsz.

By a strictly decreasing chain in a topological space $X$ we mean a well-ordered sequence $\left\{G_{\xi} ; \xi<\alpha\right\}$ of nonempty open subsets of $X$ such that for $\eta<\xi<\alpha, \bar{G}_{\xi} \subsetneq G_{\eta}$. The depth of the space $X$ is defined as the supremum of the cardinalities of its strictly decreasing chains and it will be denoted by $k(X)$.

As I. Juhàsz proved [1], for a connected topological space $X, k(X) \leqq$ $(\chi(X))^{+}$holds, where $\chi(X)$ denotes the topological character of the space $X$. He notes also that, as the long line shows, this result is the best possible in the class of connected spaces. However, the long line is not paracompact, hence I. Juhàsz raised the following problem: Is it true that, for a connected paracompact space $X, k(X) \leqq \chi(X)$ holds?

Our aim is to prove that Kowalsky's star-space [2] of weight $\omega_{1}$ is a counterexample to this conjecture. So our space $X$ is the set $\{0\} \cup$ $\bigcup\left\{\{\xi\} \times(0,1] ; \xi<\omega_{1}\right\}$ with the topology generated by the metric

$$
\begin{aligned}
\rho(0,(\xi, x))=x, & \rho((\xi, x),(\eta, y))=|y-x|, & & \text { if } \xi=\eta, \\
& =x+y, & & \text { if } \xi \neq \eta .
\end{aligned}
$$

Now the space $X$ is connected and metrizable hence paracompact and $\chi(X)=\omega_{0}$. We have only to prove that $k(X)=\omega_{1}$.

As is well known (see e.g. [3]), the open interval $(0,1)$ for each $\xi<\omega_{1}$ contains a sequence $\left\{x_{\eta}^{\xi} ; \eta<\xi\right\}$ similar to $\xi$. Put now

$$
G_{\xi}=\bigcup\left\{\{\alpha\} \times\left(x_{\xi}^{\alpha}, 1\right] ; \xi<\alpha<\omega_{1}\right\} \quad\left(\xi<\omega_{1}\right) .
$$

It is evident that the $G_{\xi}$ 's form a strictly decreasing chain of cardinality $\omega_{1}$ in $X$. Q.E.D.

Received by the editors March 2, 1973.

AMS (MOS) subject classifications (1970). Primary 54A25; Secondary 54D05.

1 This work was supported by the Italian Consiglio Nazionale delle Ricerche. This work was done while the author was at the University of Perugia.

* This article was not proofread by the author because the Amer. Math. Soc. was unable to locate him. The address given at the end of the paper is the last address given by the author.

(c) American Mathematical Society 1974 


\section{REFERENCES}

1. I. Juhàsz, A. Verbeek and N. S. Kroonenberg, Cardinal functions in topology, Mathematical Centre Tracts, no. 34, North-Holland, Amsterdam, 1971.

2. H. J. Kowalsky, Topologische Räume, Lehrbücher und Monographien aus dem Gebiete der exakten Wissenschaften, Math. Reihe, Band 26, Birkhäuser Verlag, Basil, Stuttgart, 1961, 271 pp. MR 22 \#12502.

3. F. Hausdorff, Mengenlehre, 3rd ed., de Gruyter, Berlin, 1937; English 2nd ed. transl., Chelsea, New York, 1962. MR 25 \#4999.

Department of Mathematics, University of Perugia, Perugia, Italy

Mathematical Research Institute of the Hungarian Academy of Sciences, Budapest, Hungary

Current address: Matematikai Kutató Intézet, $\overline{\mathrm{V}}$. Reáltanoda u. 13-15, Budapest, Hungary 